\title{
Evaluation of Different Substrates for Spawn Preparation of Calocybe indica and its Impact on Yield and Biological Efficiency
}

Dibakar Panda, Mohan Kumar Biswas, Bhola Nath ${ }^{1}$

10.18805/ag.D-5444

\begin{abstract}
Background: Popularities of mushrooms is because of attractive texture and delicious taste, among the cultivated mushrooms milky mushroom has ability to grow in higher temperature and is also considered to be alternative of non-veg foods for vegetarians. In India some part of the country holds good promise towards the cultivation of milky mushroom, for fast growth of mycelium or easy cultivation. This experiment is mainly focused on evaluation of yield and yield contributing characteristic of milky mushroom (Calocybe indica). Methods: The spawn production process was carried out at the Experiential Learning Unit, Mushroom Laboratory, Department of Plant Pathology, Institute of Agriculture, Palli Sikha Bhavana, Visva Bharati in the year 2018-2019. Pure culture of milky mushroom procured from Tropical Mushroom Research Centre, OUAT, Bhubaneswar and was maintained on PDA medium. Different food grains for preparation of spawn viz., wheat grain, paddy grain, bajra grain and sorghum grain were used.

Result: In the present work, we have observed that the four easily available food grains can efficiently be used as substrate for preparation of spawn. This study enables us to take decision about selection of food grains for quality spawn production.
\end{abstract}

Key words: Calocybe indica, Mushroom, Mycelium, Spawn substrates, Yield.

\section{INTRODUCTION}

The existence of mushroom is of million years ago and it is known for its food value including nutrition, texture and flavor. The productivity of mushroom is much higher so it can lower the malnutrition in many countries. Cultivation of mushroom is economical in which agricultural wastes are convert into valuable food (Yella et al., 2021).

Spawn consists of mushroom mycelium which provides support for better growth and nutrition to the mushroom mycelium. The fully grown mushroom mycelium use as planting material for preparation of beds by the mushroom farmers regarded as spawn. This spawn is treated as equivalent as seed of higher plant (Pathak et al., 2000). During the cultivation of mushroom spawn is known as inoculum and the medium cover with mycelium prepared from pure culture of particular mushrooms strain. Producing of spawn is carried under controlled environment in which mycelium of mushroom grown by increasing over sterilized grains i.e., wheat grain, bajra grain, paddy grain and sorghum, grain etc. (Jain and Vyas, 2005).

Calocybe indica has the quality to cultivate in tropical and subtropical region, so milky mushroom has ability to grow on temperature more than $30^{\circ} \mathrm{C}$ where no other mushrooms like oyster, paddy straw and button can grow better in summer season due to their temperature sensibility (Subbiah and Balan, 2015). This mushroom ( $C$. indica) has the alternating option at this temperature and milky mushroom has the high biological efficiency i.e., more than 90 per cent with whitish fruiting body and long shelf-life. Due to the exceptional character the present research work targets to prepare spawn by using different cereal grains as
Department of Plant Pathology, Institute of Agriculture, Visva Bharati, Sriniketan-731 236, West Bengal, India.

'Department of Agricultural Statistics, Institute of Agriculture, Visva Bharati, Sriniketan-731 236, West Bengal, India.

Corresponding Author: Dibakar Panda, Department of Plant Pathology, Institute of Agriculture, Visva Bharati, Sriniketan-731 236, West Bengal, India. Email: dibakar097@gmail.com

How to cite this article: Panda, D., Biswas, M.K. and Nath, B. (2021). Evaluation of Different Substrates for Spawn Preparation of Calocybe indica and its Impact on Yield and Biological Efficiency. Agricultural Science Digest. DOI: 10.18805/ag.D-5444.

Submitted: 07-07-2021 Accepted: 18-10-2021 Online: 18-11-2021

substrate for spawn preparation and to observe the effects of the same on growth attributing characters of milky mushroom.

\section{MATERIALS AND METHODS}

The spawn production process was carried out at the Experiential Learning Unit, Mushroom Laboratory, Dept. of Plant Pathology, Institute of Agriculture, Palli Sikha Bhavana, Visva Bharati in the year 2018-2019. Pure culture of milky mushroom procured from Tropical Mushroom Research Centre, OUAT, Bhubaneswar and was maintained on Potato Dextrose Agar (PDA) medium. Same medium was used by Thulasi et al. (2010) for maintaining the pure cultures.

Dehariya and Vyas (2015) used wheat, jowar and sorghum grains for the preparation of spawn. In the present work, four cereal grains like wheat grain, paddy grain, bajra grain and sorghum grains are used as spawn substrate 
(Table 1). The inert matters in these grains were removed manually and washed thoroughly. These grain substrates were boiled in hot water for 30 minutes, then allowed for cooling for a while and drained out excess water. Then allowed to dry by spreading over polythene sheet. After drying the grains, calcium carbonate was added @ $2 \%$ for neutralizing the substrates. The sterilized (Hot air oven $160^{\circ} \mathrm{C}$ for 2 hours) glass bottles were used for filling of substrates. After filling $3 / 4^{\text {th }}$ volume of these bottles, mouth of the bottles were plugged by using non-absorbent cotton. Then wrapping of the neck of the bottles are done by using paper and rubber bands. Following this process, the bottles were kept in autoclave for sterilization where the temperature was maintained at $121.6^{\circ} \mathrm{C}$ for 2 hours. After sterilization, the bottles were removed from the autoclave and placed in a room for cooling. After cooling, the bottles were place into laminar air flow chamber for inoculation. Before inoculation, the laminar air flow chamber was sterilized by UV rays and floor were sterilized by alcohol. These bottles were inoculated aseptically by using mother culture and placed into BOD incubation chamber for growth. In BOD, the temperature was maintained at $27-30^{\circ} \mathrm{C}$. After some days the mycelium were colonized in those bottles, then it is used for preparation of mushroom beds.

All the bed substrates were chemically sterilized with $500 \mathrm{ppm}$ formalin and $75 \mathrm{ppm}$ carbendazim solution. Mixture of soil and sand (2:1) were used as casing material and those casing materials were sterilized in autoclave for 2 hours at $121.6^{\circ} \mathrm{C}$. After following all the necessary processes, the yield and various morphological characters were recorded.

\section{RESULTS AND DISCUSSION}

As per the analysis is concerned all the treatment and interactions were significant (at $5 \%$ level of significance) to highly significant (at 1\% level of significance) that further suggests the post-hoc comparison of all of them to get the best treatment. To do so we have used least significant difference (LSD) Method of treatment comparison and obtained critical difference (CD) value separately for all the treatments and interactions of all the parameters. By arranging treatments in their descending order and taking

Table 1: List of treatment combinations.

\begin{tabular}{ll}
\hline Treatment & Combination \\
\hline A1B1 & Wheat grain + paddy straw \\
A1B2 & Paddy grain + paddy straw \\
A1B3 & Bajra grain + paddy straw \\
A1B4 & Sorghum grain + paddy straw \\
A2B1 & Wheat grain + paddy straw and garden waste \\
A2B2 & Paddy grain + paddy straw and garden waste \\
A2B3 & Bajra grain + paddy straw and garden waste \\
A2B4 & Sorghum grain + paddy straw and garden waste \\
\hline
\end{tabular}

Table 2: Days required for growth of mycelium on spawn substrates.

\begin{tabular}{llcc}
\hline CD (5\%) & Treatments & Difference & Significance \\
\hline 1.79 & T4-T2 (17.60-16.40) & 1.20 & NS \\
& T2-T3 (16.40-13.80) & 2.60 & $\mathrm{~S}$ \\
& T3-T1 (13.80-12.40) & 1.40 & NS \\
\hline
\end{tabular}

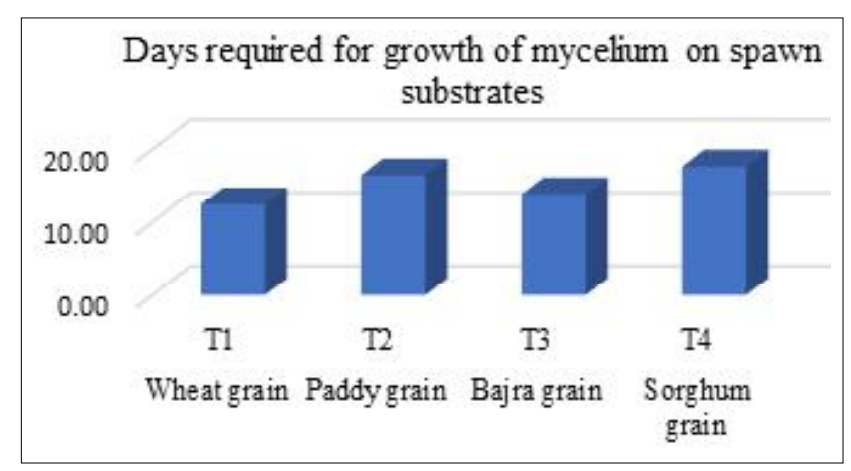

Fig 1: Days required for growth of mycelium on spawn substrates.

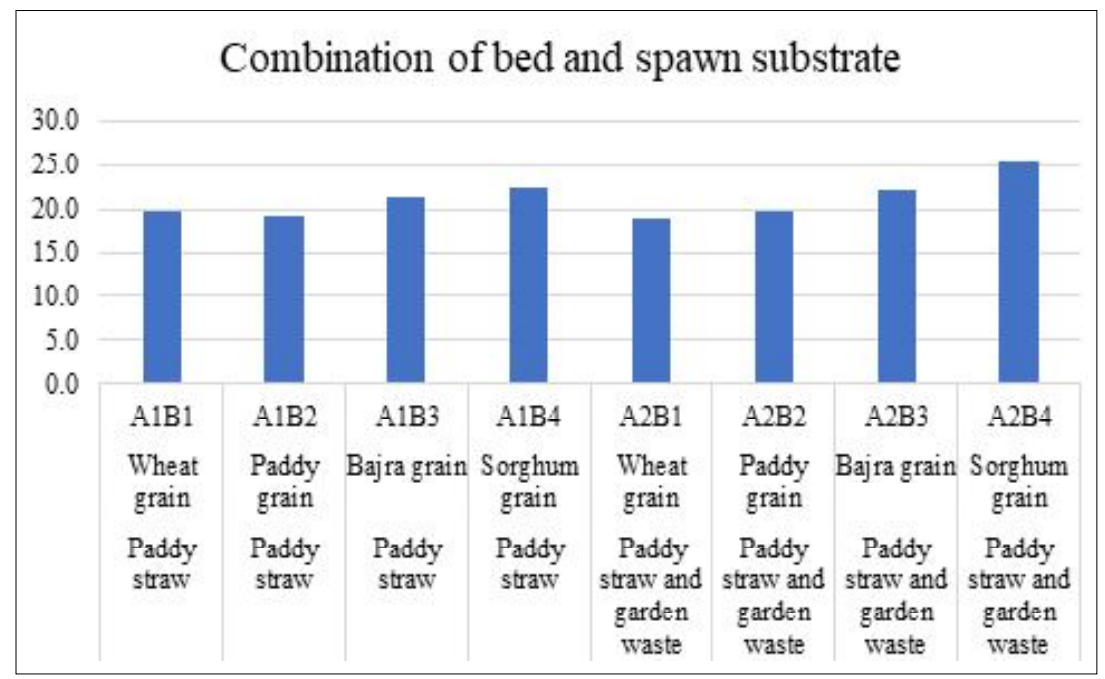

Fig 2: Average number of days for spawn run. 
the pairwise difference of them, we have chosen the best treatments of $A, B$ and $A B$ separately with the help of $C D$ for all the biological parameters.

Fig 1 shows the minimum number of days required for the growth of mycelium on spawn substrates and it is observed in T3 (13.80 days) which was resulted in the analysis of observed data (Table 2). In interaction of both bed substrate and spawn substrate the combination of A1B4 i.e., paddy straw added with spawn prepared from sorghum grain (Fig 2) gives the spawn run in the minimum number of days (22.30 days) the same is evident in (Table 3 ) similar finding was reported by Senthilnambi et al. (2011). Fig 3

Table 3: Days required for spawn run.

\begin{tabular}{|c|c|c|c|c|}
\hline Name & CD (5\%) & Treatments & Difference & Significance \\
\hline $\bar{A}$ & 0.810 & A2-A1 (21.50-20.67)* & 0.83 & $S$ \\
\hline \multirow[t]{3}{*}{ B } & 1.145 & B4-B3 $(23.83-21.67)^{*}$ & 2.16 & $S$ \\
\hline & & B3-B2 $(21.67-19.50)^{*}$ & 2.17 & $S$ \\
\hline & & B2-B1 (19.50-19.33) & 0.17 & NS \\
\hline \multirow[t]{7}{*}{$A B$} & 1.619 & A2B4-A1B4 (25.30-22.30)* & 3.00 & $S$ \\
\hline & & A1B4-A2B3 (22.30-22.00) & 0.30 & NS \\
\hline & & A2B3-A1B3 (22.00-21.30) & 0.70 & NS \\
\hline & & A1B3-A1B1 (21.30-19.70) & 1.60 & NS \\
\hline & & A1B1-A2B2 (19.70-19.70) & 0.00 & NS \\
\hline & & A2B2-A1B2 (19.70-19.30) & 0.40 & NS \\
\hline & & A1B2-A2B1 (19.30-19.00) & 0.30 & NS \\
\hline
\end{tabular}

Note: Figures in the parentheses are the average number of days to spawn run substrates for treatment respective combinations.

Table 4: Days to pin head formation.

\begin{tabular}{|c|c|c|c|c|}
\hline Name & CD (5\%) & Treatments & Difference & Significance \\
\hline $\bar{A}$ & 0.656 & A2-A1 $(21.83-20.68)^{*}$ & 1.15 & $S$ \\
\hline \multirow[t]{3}{*}{ B } & 0.928 & B3-B4 $(22.65-22.50)^{*}$ & 0.15 & NS \\
\hline & & B4-B2 (22.50-20.20) & 2.30 & $S$ \\
\hline & & B2-B1 (20.20-19.65) & 0.55 & NS \\
\hline \multirow[t]{7}{*}{$A B$} & 1.313 & A1B4-A1B3 (23.70-23.00) & 0.70 & NS \\
\hline & & A1B3-A2B3 (23.00-22.30) & 0.70 & NS \\
\hline & & A2B3-A2B1 (22.30-22.00) & 0.30 & NS \\
\hline & & A2B1-A2B2 (22.00-21.70) & 0.30 & NS \\
\hline & & A2B2-A2B4 (21.70-21.30) & 0.40 & NS \\
\hline & & A2B4-A1B2 $(21.30-18.70)^{*}$ & 2.60 & $\mathrm{~s}$ \\
\hline & & A1B2-A1B1 (18.70-17.30)* & 1.40 & s \\
\hline
\end{tabular}

Note: Figures in the parentheses are the average number of days to Pin head formation substrates for treatment respective combinations.

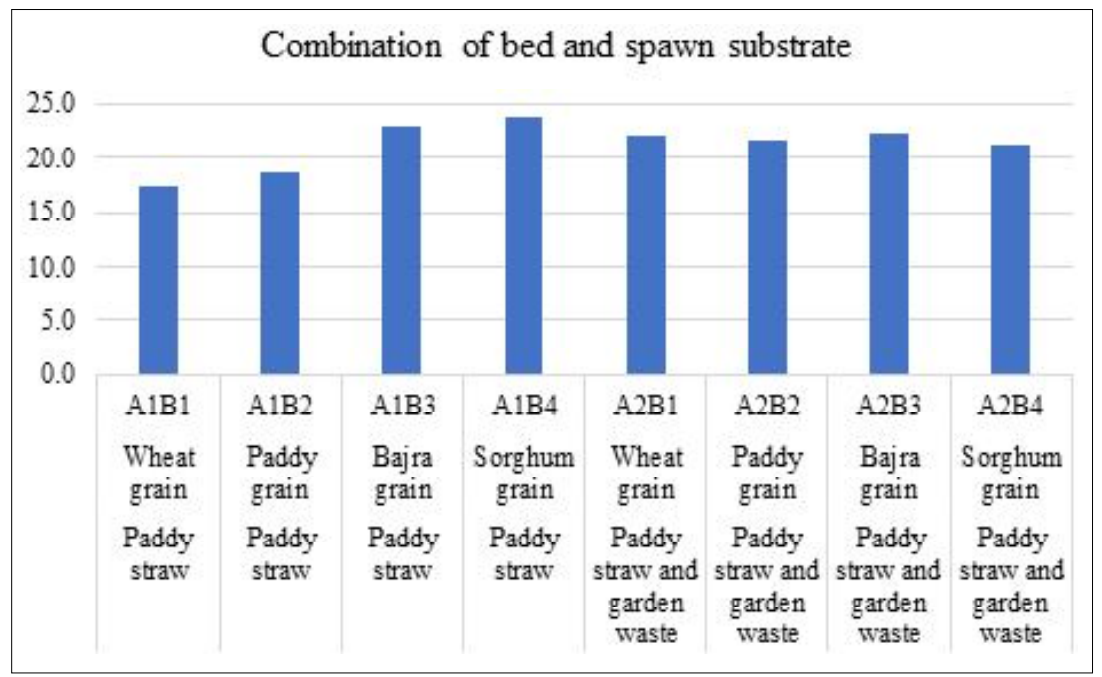

Fig 3: Average number of days for pin head formation. 
Table 5: Average stalk length.

\begin{tabular}{|c|c|c|c|c|}
\hline Name & CD (5\%) & Treatments & Difference & Significance \\
\hline $\bar{A}$ & 0.305 & A1-A2 $(14.15-13.67)^{*}$ & 0.48 & $S$ \\
\hline \multirow[t]{3}{*}{ B } & 0.431 & B4-B3 $(16.06-14.79)^{*}$ & 1.27 & NS \\
\hline & & B3-B1 (14.79-13.74) & 1.05 & $S$ \\
\hline & & B1-B2 (13.74-11.04) & 2.70 & $S$ \\
\hline \multirow[t]{7}{*}{$A B$} & 0.610 & A1B1-A2B4 (17.30-17.10)* & 0.20 & NS \\
\hline & & A2B4-A2B3 (17.10-15.30) & 1.80 & $S$ \\
\hline & & A2B3-A1B4 (15.30-15.00) & 0.30 & NS \\
\hline & & A1B4-A1B3 (15.00-14.20) & 0.80 & NS \\
\hline & & A1B3-A2B2 (14.20-12.10)* & 2.10 & $S$ \\
\hline & & A2B2-A2B1 (12.10-10.10)* & 2.00 & $S$ \\
\hline & & A2B1-A1B2 (10.10-10.00) & 0.10 & NS \\
\hline
\end{tabular}

Note: Figures in the parentheses are the average stalk length of mushrooms on substrates for treatment respective combinations.

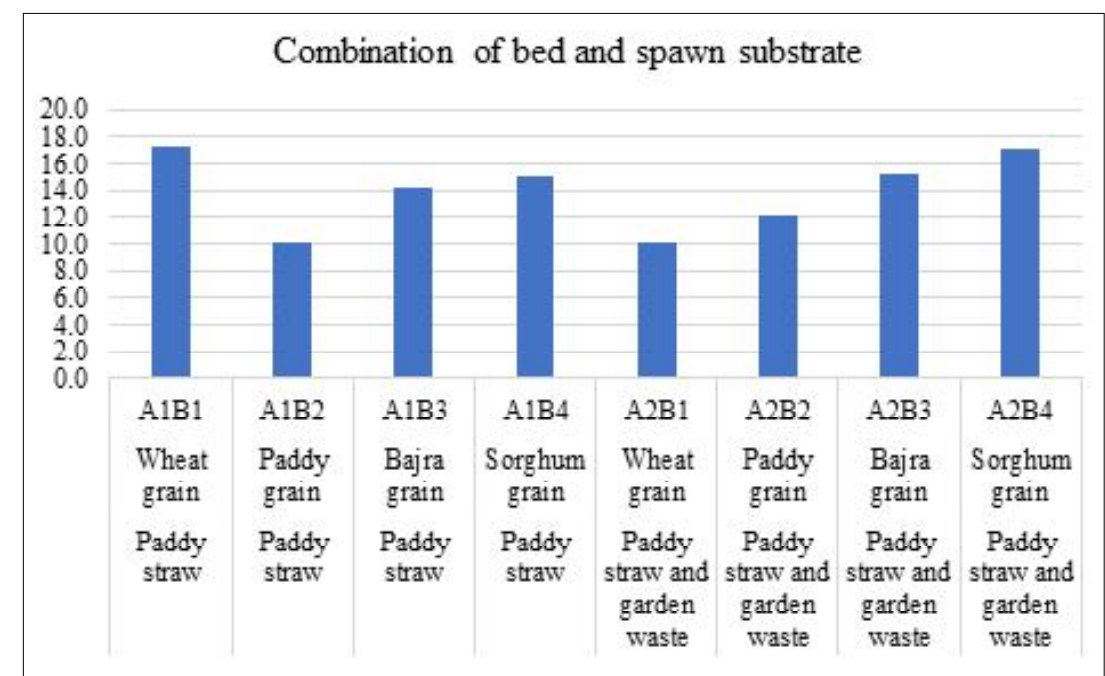

Fig 4: Average stalk length of mushrooms.

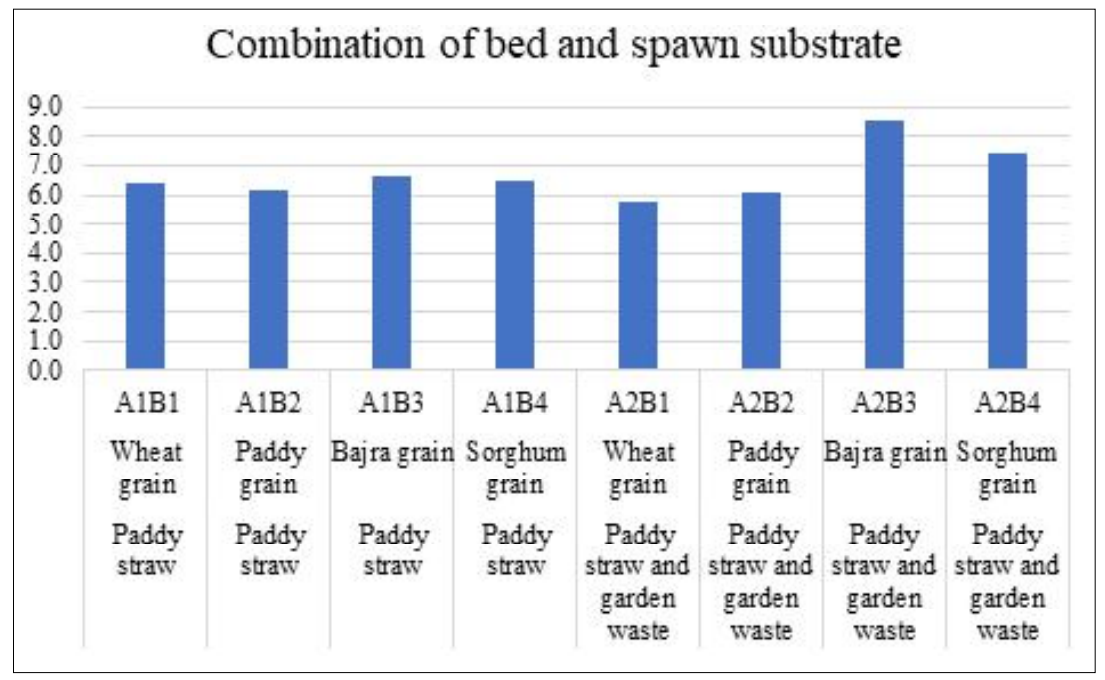

Fig 5: Average pileus diameter of mushrooms. 
shows paddy straw added with spawn prepared from wheat grain i.e., A1B1 gives the pin head formation in the minimum number of days (17.30 days) data was analysed and tabulated in (Table 4) similar results were reported by Purkayastha and Nayak (1981). Fig 4 shows paddy straw added with spawn prepared from wheat grain i.e., A1B1 gives the maximum average of stalk length $(17.10 \mathrm{~cm})$ the same is evident in (Table 5). The combination of paddy straw and garden waste substrates added with spawn prepared from bajra grain (Fig 5) i.e., A2B3 gives the maximum average of pileus diameter $(8.5 \mathrm{~cm})$ data was analysed and tabulated in (Table 6). The combination of paddy straw and garden

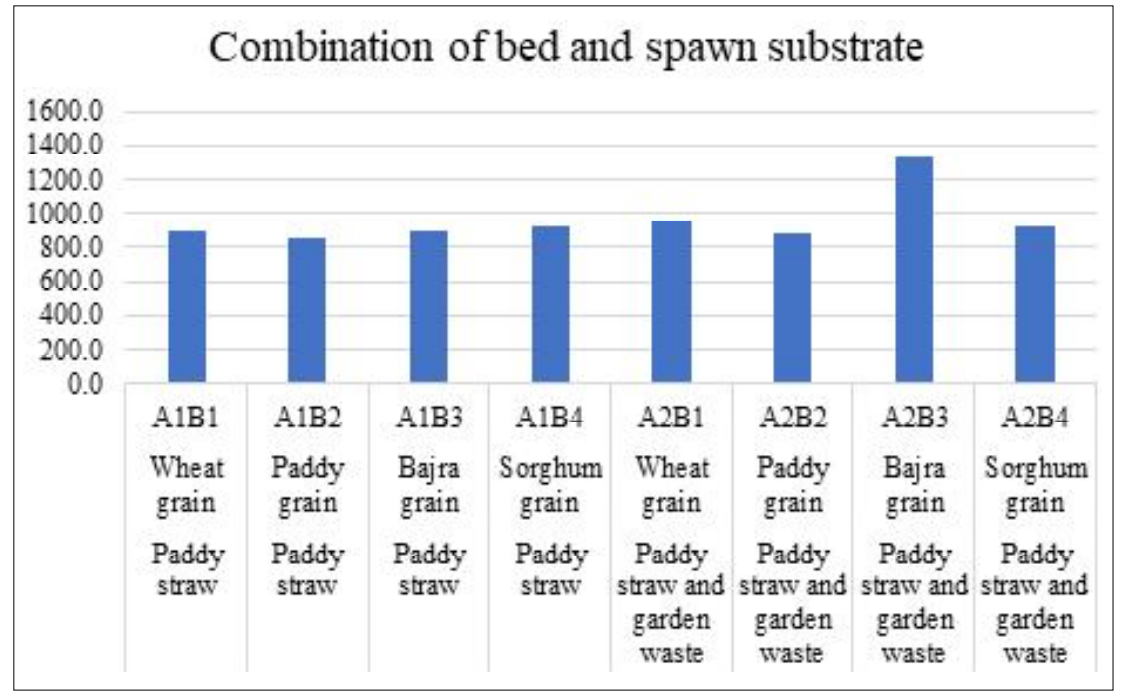

Fig 6: Average yield for different treatment combinations.

Table 6: Pileus diameter.

\begin{tabular}{|c|c|c|c|c|}
\hline Name & CD $(5 \%)$ & Treatments & Difference & Significance \\
\hline $\bar{A}$ & 0.314 & A2-A1 $(6.96-6.44)^{*}$ & 0.52 & $\mathrm{~S}$ \\
\hline \multirow[t]{3}{*}{ B } & 0.444 & B3-B4 $(7.56-6.96)^{*}$ & 0.60 & $S$ \\
\hline & & B4-B2 (6.96-6.17) & 0.79 & $\mathrm{~S}$ \\
\hline & & B2-B1 (6.17-6.09) & 0.08 & NS \\
\hline \multirow[t]{7}{*}{$A B$} & 0.628 & A2B3-A2B4 $(8.5-7.4)^{*}$ & 1.10 & $S$ \\
\hline & & A2B4-A1B3 (7.40-6.60) & 0.80 & $S$ \\
\hline & & A1B3-A1B4 (6.60-6.50) & 0.10 & NS \\
\hline & & A1B4-A1B1 (6.50-6.40) & 0.10 & NS \\
\hline & & A1B1-A1B2 (6.40-6.20) & 0.20 & NS \\
\hline & & A1B2-A2B2 (6.20-6.10) & 0.10 & NS \\
\hline & & A2B2-A2B1 (2.8-2.5) & 0.30 & $\mathrm{~s}$ \\
\hline
\end{tabular}

Note: Figures in the parentheses are the average Pileus diameter of mushrooms on substrates for treatment respective combinations.

Table 7: Yield (g).

\begin{tabular}{|c|c|c|c|c|}
\hline Name & CD (5\%) & Treatments & Difference & Significance \\
\hline A & 78.793 & A2-A1 (1027.50-897.50)* & 130.00 & $\mathrm{~s}$ \\
\hline \multirow[t]{3}{*}{ B } & 111.430 & B3-B1 $(1121.67-929.17)^{*}$ & 192.50 & $S$ \\
\hline & & B1-B4 (929.17-927.50) & 1.67 & NS \\
\hline & & B4-B2 (927.50-871.67) & 55.83 & NS \\
\hline \multirow[t]{7}{*}{$A B$} & 157.586 & A2B3-A2B1 $(1340-955)^{*}$ & 385.00 & $S$ \\
\hline & & A2B1-A2B4 (955-931.7) & 23.30 & NS \\
\hline & & A2B4-A1B4 (931.70-923.30) & 8.40 & NS \\
\hline & & A1B4-A1B1 (923.30-903.30) & 20.00 & NS \\
\hline & & A1B1-A1B3 (903.30-903.30) & 0.00 & NS \\
\hline & & A1B3-A2B2 (903.30-883.30) & 20.00 & NS \\
\hline & & A2B2-A1B2 (883.30-860.00) & 23.30 & NS \\
\hline
\end{tabular}

Note: Figures in the parentheses are the average yield of mushrooms on substrates for treatment respective combinations. 


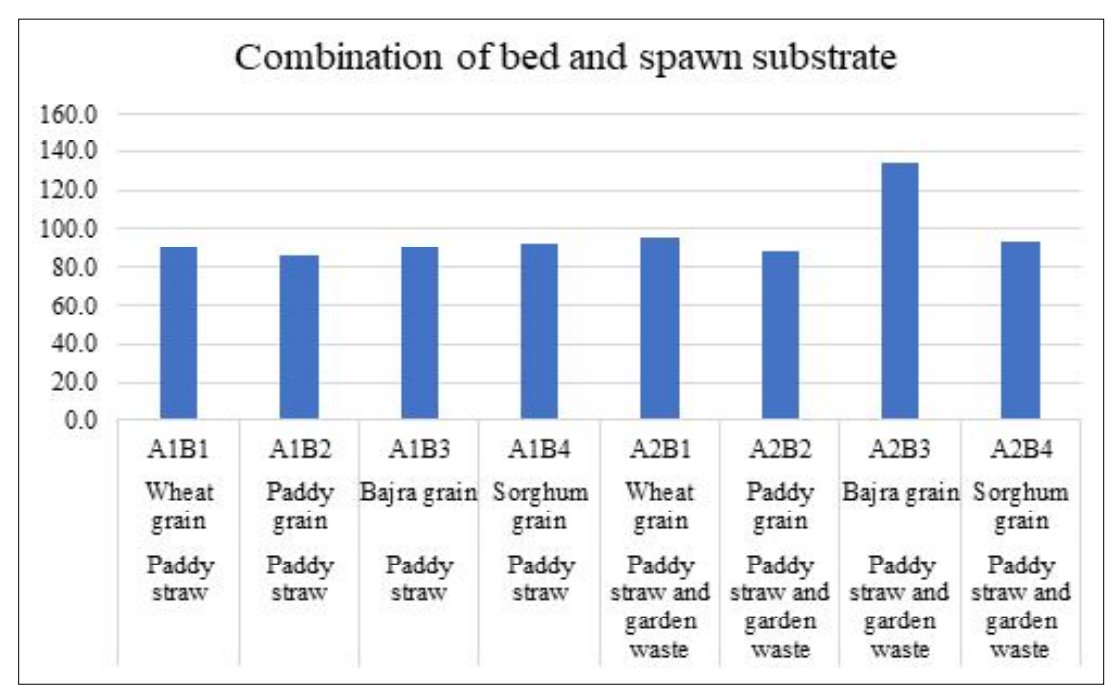

Fig 7: Biological efficiency of different treatment combinations.

Table 8: Biological efficiency.

\begin{tabular}{|c|c|c|c|c|}
\hline Name & CD $(5 \%)$ & Treatments & Difference & Significance \\
\hline A & 7.904 & A2-A1 $(102.58-89.75)^{*}$ & 12.83 & S \\
\hline \multirow[t]{3}{*}{ B } & 11.178 & B3-B1 $(112.17-92.83)^{*}$ & 19.34 & $S$ \\
\hline & & B1-B4 (92.83-92.67) & 0.16 & NS \\
\hline & & B4-B2 (92.67-87.00) & 5.67 & NS \\
\hline \multirow[t]{7}{*}{$A B$} & 15.809 & A2B3-A2B1 (134.00-95.50)* & 38.50 & $S$ \\
\hline & & A2B1-A2B4 (95.50-93.00) & 2.50 & NS \\
\hline & & A2B4-A1B4 (93.00-92.30) & 0.70 & NS \\
\hline & & A1B4-A1B1 (92.30-90.30) & 2.00 & NS \\
\hline & & A1B1-A1B3 (90.30-90.30) & 0.00 & NS \\
\hline & & A1B3-A2B2 (90.30-88.00) & 2.30 & NS \\
\hline & & A2B2-A1B2 (88.00-86.00) & 2.00 & NS \\
\hline
\end{tabular}

Note: Figures in the parentheses are the average biological efficiency of mushrooms on substrates for treatment respective combinations.

waste substrates added with spawn prepared from bajra grain (Fig 6) i.e., A2B3 gives the maximum yield (1340 kg) as well as biological efficiency (134.0\%) the similar result is evident in the study of Vijaykumar et al. (2014) (Table 7 and 8). Minimum days (13.80 days) required for growth of mycelium on spawn substrates recorded from bajra grain, maximum biological efficiency was recorded from spawn prepared from bajra grain (Fig 7) followed by the spawn prepared from wheat grain (95.50\%). Maximum yield was recorded from spawn prepared from bajra grain $(1340 \mathrm{~g})$ followed by the spawn prepared from wheat grain $(955.0 \mathrm{~g})$, primordia initiation occurred prior in spawn prepared from wheat grain (17.30 days) and later in spawn prepared from paddy grain (18.70 days). The maximum stalk length observed with spawn prepared from wheat grain $(17.30 \mathrm{~cm})$. The maximum pileus diameter observed with spawn prepared from bajra grain $(8.50 \mathrm{~cm})$. The earliest spawn run observed in spawn prepared from sorghum grain (22.30 days). In the present study, it is found that bajra grain is the most efficient spawn substrate for commercial cultivation of $C$. indica, which is similar to the findings of Maurya et al. (2019).

\section{CONCLUSION}

Yield contributing factors of $C$ indica were evaluated on the basis of spawn prepared by using grain substrates viz., wheat, paddy, bajra, sorghum grains.

\section{ACKNOWLEDGEMENT}

The authors are highly grateful to the Head, Department of plant pathology, Institute of Agriculture, Palli Shikha Bhavan, Visva Bharati University, Sriniketan for providing lab facilities for carrying out this research work.

\section{REFERENCES}

Dehariya, P. and Vyas, D. (2015). Evaluation of different spawns and substrates on growth and yield of Pleurotus sajorcaju. International Journal of Recent Scientific Research Research. 6(3): 2908-2911. 
Jain, A.K. and Vyas, D. (2005). Comparative study on the yield of three Pleurotus sp. grown in several lignocelluloses Byproducts. J. Basic Appl. Mycol. 4: 155-157.

Maurya, A.K., John, V., Murmu, R. and Simon, S. (2019). Impact of different substrates for spawn production and Production of milky mushroom (Calocybe indica). International Journal of Pharma and Bio Sciences. 10(3): (B) 5-10.

Pathak, V. N., Yadav, N. and Gour, M. (2000). Mushroom Production and Processing Technology. Agrobios. pp. 93-100.

Purkayastha, R.P. and Nayak, D. (1981). Development of cultivation method and analysis of protein of promising edible mushroom, Mushroom Calocybe indica ( $P$ and $C$ ). Mushroom Science. 11: 697-713.

Senthilnambi, D., Balabaskar, P. and Eswaran, A. (2011). Impact of different spawn substrates on yield of Calocybe indica. African Journal of Agricultural Research. 6(12): 39463948.
Subbiah, K.A. and Balan, V. (2015). A Comprehensive Review of Tropical Milky White Mushroom (Calocybe indica $\mathrm{P}$ and C). Mycobiology. 43(3): 184-194.

Thulasi, E.P., Thomas, D., Ravichandran, B. and Madhusudhanan, K. (2010). Mycelial culture and spawn production of two oyster Mushrooms, Pleurotus florida and Pleurotuseous on Different Substrates. International Journal of Biological Technology. 1(3): 39-42.

Vijaykumar, G., John, P. and Ganesh, K., (2014). Selection of substrates for the cultivation of milky mushroom (Calocybe indica $\mathrm{P}$ and $\mathrm{C}$ ). Indian Journal of Traditional Knowledge. 13(2): 434-436.

Yella, V.K., Chadrapati, A., Kuri, A., Miglani, I. andrews, A.A. and Singh, S. (2021). Cultivation technology and spawn production of Volvariella volvacea: Paddy straw mushroom. The Pharma Innovation Journal. 10(5): 1184-1190. 